\title{
Modeling Spatial Variation in Stand Volume of Acacia mangium Plantations Using Geographically Weighted Regression
}

\author{
Tiryana, T., Tatsuhara, S. \& Shiraishi, N.
}

Keywords: Geographically weighted regression (GWR), spatial variation, stand volume

Abstract: Stand volume can be estimated from other stand variables by using multiple linear regression (MLR) or other ordinary regression models. MLR, however, only produces global parameter estimates that cannot reveal spatial variations in stand variables. In this study, we used a geographical weighted regression (GWR) method to investigate local spatial variations in the relationship between stand volume, stand age, and basal area of Acacia mangium plantations, and to examine whether a GWR model could provide better prediction accuracy than an MLR model. Stand data and geographical coordinates were obtained from 247 plantation sample plots. We analyzed the data using MLR and GWR methods by formulating a linear model that relates stand volume to stand age and basal area. Performance of the GWR model was compared with the MLR model in terms of their parameter estimates and goodness-of-fit statistics. We found that the GWR model was not only able to reveal local spatial variations in the relationship between stand volume, stand age, and basal area, but it also produced better prediction accuracy than the MLR model. The GWR model reduced AIC by $2 \%$, increased $R_{a d j}^{2}$ up to $3 \%$, and reduced RMSE by $14 \%$, compared with those of the MLR model. The GWR model, therefore, could be useful for modeling spatial variations in stand attributes that cannot be revealed by ordinary regression models.

Received July 22, 2009; Accepted November 30, 2009 


\section{Introduction}

Information about forest resources is essential for forest managers to manage their forests in appropriate ways. Among others, stand volume is still considered to be an important stand variable (Husch et al., 2003), which is commonly used by forest managers to estimate financial benefits from their forests. Stand volume can also be used to quantify forest biomass by using a volume-biomass model (e.g., Fang et al., 1998). Estimation of stand volume is therefore an important aspect in forest management.

Stand volume can be estimated from other stand variables (e.g., basal area, height, age, and the number of trees) by using a stand volume equation (Clutter et al., 1988, Husch et al., 2003). Traditionally, ordinary linear or nonlinear regression (see e.g., Draper and Smith, 1998) is often used to develop a stand volume equation. For instance, Vélez and Valle (2007) used a simple power model to estimate stand volume from basal area of Acacia mangium plantations in Colombia. There is no doubt that a stand volume equation derived from an ordinary regression model has provided a useful tool for forest management. The ordinary regression model, however, has a limitation because it produces a global model that assumes the stationary of model parameters, meaning that the effect of each predictor is constant over the whole study area. For instance, if a global model estimates stand volume from basal area, then the estimated stand volume at a certain location will be the same as that of other locations with the same level of basal area. In reality, it is not always true because the relationship between basal area and stand volume might vary from one location to another as the result of local spatial variations. Because the global model cannot represent spatial variations in the relationships among stand variables, it would produce less accurate predictions. It is therefore the global model would less appropriate for detail spatial forest planning in which 
precise information of forest resources at every location is desirable.

One of the promising methods for modeling local spatial variations is geographically weighted regression (GWR, see Fotheringham et al., 2002). The basic idea of GWR is capturing spatial variation by fitting regression models at each location. It means that each location has a set of model parameters that may differ from other locations. Thus, GWR extends a global regression model to account for spatial nonstationary in the relationship between observed variables across space (Fotheringham et al., 2002, Miller et al., 2007).

Although GWR has initially gained popularity in the fields of human geography and socio-economics (Fotheringham et al., 2002, Kupfer and Farris, 2007, Miller et al., 2007), several studies have also confirmed the usefulness of this method for forestry applications. Zhang et al. (2004) showed that GWR outperformed ordinary regression for predicting individual tree heights of a forest stand. Zhang and Shi (2004) as well as Kupfer and Farris (2007) provided other evident that basal area was better predicted by using GWR rather than ordinary regression. Similarly, Wang et al. (2005) also concluded that GWR was better than ordinary regression for predicting net primary production, whereas Kimsey et al. (2008) confirmed such conclusion when they used GWR for predicting site index.

While those previous studies have used GWR for modeling spatial variations in tree heights, basal area, net primary production, and site index of forest stands, there is still lack of study that used GWR for modeling spatial variations in stand volume, especially for Acacia mangium plantations. In this study, we used GWR to investigate local spatial variations in the relationship between stand volume, stand age, and basal of Acacia mangium plantations in West Java, Indonesia. We were particularly interested to explore whether local variations of stand age and basal area might give different effects to stand volume and to 
examine whether GWR model could provide better prediction accuracy than MLR model.

\section{Material and Methods}

\subsection{Data}

This study used forest inventory data collected from Acacia mangium plantations located in Bogor, West Java, Indonesia (6 $6^{\circ} 21^{\prime} 0^{\prime \prime}-6^{\circ} 24^{\prime} 3^{\prime \prime}$ S, $\left.106^{\circ} 26^{\prime} 7^{\prime \prime}-106^{\circ} 29^{\prime} 58^{\prime \prime} \mathrm{E}\right)$. The total plantation areas is 1466.44 ha, which is mostly located on flat and gently undulating terrains (0-8\%) with a mean annual rainfall of $3000 \mathrm{~mm}$. The plantations are usually thinned at 3, 5, and 7 years, which are then harvested at 10-12 years to produce timbers for building and furniture materials (Perum Perhutani, 2006).

Data on stand volume, stand age, and basal area were collected from 247 circular sample plots with sizes ranging from 0.02 to 0.1 ha. To cover the spatial variations of plantations, the sample plots were established systematically (with interval of about $200 \mathrm{~m}$ ) in 16 compartments within the study area. Besides stand variables data, the geographical coordinates (UTM system at zone 48S) of plot centers were also used in data analysis.

\subsection{Statistical analysis}

The data were analyzed using ordinary multiple linear regression (MLR) and GWR methods. The results of both methods were then compared and evaluated in terms of their parameter estimates and goodness-of-fit statistics.

We first explored the data set and found that stand volume had strong correlations with stand age $(r=0.62)$ and basal area $(r=0.94)$, while there was no strong correlation $(r=0.34)$ between stand age and basal area. These results suggested that stand age and basal area 
were appropriate predictors for stand volume, besides they are easier to measure in the field than other stand variables (e.g, height and site index). The stand volume (response variable) was assumed to be a random variable from a normally distributed population. We formulated the global model using MLR as follows:

$$
y_{i}=\beta_{0}+\beta_{1} x_{1 i}+\beta_{2} x_{2 i}+\varepsilon_{i}
$$

where $y_{i}$ is stand volume ( $\mathrm{m}^{3} / \mathrm{ha}$ ), $x_{1 i}$ is stand age (years), $x_{2 i}$ is basal area $\left(\mathrm{m}^{2} / \mathrm{ha}\right)$ at sample plot $i, \beta_{0}, \beta_{1}, \beta_{2}$ are model parameters, and $\varepsilon_{i}$ is random error term that follows a normal distribution with mean zero and variance $\sigma^{2}$. Model parameters were estimated using ordinary least squares (OLS) as commonly used in MLR (see Draper and Smith, 1998):

[2] $\quad \hat{\boldsymbol{\beta}}=\left({ }^{t} \boldsymbol{X} \boldsymbol{X}\right)^{-1}{ }^{t} \boldsymbol{X} \boldsymbol{y}$

where ${ }^{t}$ denotes the transpose of a matrix. The analysis of MLR model was performed using $\mathrm{R}$ version 2.8.1 (R Development Core Team, 2009).

While global models only produce single coefficient for each parameter (as Eq. [1]), GWR generates local coefficients for each parameter by integrating geographical coordinates of the sample plots (Fotheringham et al., 2002). In GWR, therefore, the relationship between stand volume, stand age, and basal area was formulated as follows:

$$
y_{i}=\beta_{0\left(u_{i}, v_{i}\right)}+\beta_{1\left(u_{i}, v_{i}\right)} x_{1 i}+\beta_{2\left(u_{i}, v_{i}\right)} x_{2 i}+\varepsilon_{i}
$$

where $\left(u_{i}, v_{i}\right)$ are geographical coordinates of sample plot $i$.

It is clear from [1] and [3] that GWR extends MLR model by generating local coefficients for each parameter. GWR estimates local coefficients at a sample point based on its neighboring observations within a certain distance (called as a bandwidth) that are weighted using a weighting function (called as a spatial kernel). Observations closer to 
the sample point will give more weight or influence in determining the local coefficients. Thus, the weights of neighboring observations are controlled by a bandwidth (expressed in radius or number of observations), which is either fixed bandwidth or adaptive bandwidth, of a spatial kernel (Fotheringham et al., 2002). In this study, we used the adaptive bandwidth with Gaussian kernel function as follows:

[4] $\quad w_{i j}=\exp \left\{-0.5\left(d_{i j} / h\right)^{2}\right\}$

where $w_{i j}$ is a weight for an observation at location $j$ around the sample plot $i, d_{i j}$ is distance between locations $i$ and $j$, and $h$ is bandwidth. To obtain an optimal bandwidth, we used the minimization of AIC defined as follows (Fotheringham et al., 2002):

[5] $\quad \mathrm{AIC}=2 n \log \left(\hat{\sigma}^{2}\right)+n \log (2 \pi)+n\left\{\frac{n+\operatorname{tr}(\boldsymbol{S})}{n-2-\operatorname{tr}(\boldsymbol{S})}\right\}$

where $n$ is the total number of sample plots, $\hat{\sigma}$ is the estimated standard deviation of the error term, and $\operatorname{tr}(\boldsymbol{S})$ is the trace of hat matrix $\boldsymbol{S}$ that maps the vector of estimated values into the observed values (i.e., $\hat{\boldsymbol{y}}=\boldsymbol{S y}$ ). In our study, the optimal bandwidth was $4.8 \%$ of the total sample that is closest to a certain data point (in average about 11 of 247 observations). To ensure the appropriateness of the kernel function, we also tested Gaussian and bi-square with fixed bandwidth kernel functions, but, none of them produced lower AIC than that of the Gaussian kernel with adaptive bandwidth.

The weights derived from the Gaussian kernel function were then used by GWR to estimate local coefficients for each parameter using a weighted least squares regression (Fotheringham et al., 2002):

$[6]$

$$
\hat{\boldsymbol{\beta}}_{i}=\left({ }^{t} \boldsymbol{X} \boldsymbol{W}_{i} \boldsymbol{X}\right)^{-1}{ }^{t} \boldsymbol{X} \boldsymbol{W}_{i} \boldsymbol{y}
$$


where $\boldsymbol{W}_{i}$ is a spatial weighting matrix of the form:

[7] $\quad \boldsymbol{W}_{i}=\left(\begin{array}{cccc}w_{i 1} & 0 & \cdots & 0 \\ 0 & w_{i 2} & \cdots & 0 \\ \vdots & \vdots & \ddots & \vdots \\ 0 & 0 & \cdots & w_{i n}\end{array}\right)$

All calculations of GWR were performed using spgwr package of the $\mathrm{R}$ software (Bivand and $\mathrm{Yu}, 2009)$. Further statistical theories related to GWR can be found in Fotheringham et al. (2002) and some papers (e.g., Zhang et al., 2004, Zhang and Shi, 2004).

The presence of non-stationary in the relationship between stand volume, stand age, and basal area was examined by comparing the model parameters of GWR and MLR. If the inter-quartile range of GWR is greater than the range of $\beta \pm$ standard error (SE) of MLR, this indicates the presence of non-stationary in model parameters (Fotheringham et al., 2002). To illustrate spatial variations in the relationship between stand volume, stand age, and basal area, we mapped the local parameter estimates and model $R_{a d j}^{2}$. In addition, we further explored correlation between GWR coefficient estimates to examine the possibility of multicollinearity among the local coefficients as studied in detail by Wheeler and Tiefelsdorf (2005). We then compared the goodness-of-fit statistics of MLR and GWR models by using AIC, adjusted coefficient of determination $\left(R_{a d j}^{2}\right)$, and root mean square error (RMSE) values. The model with the highest AIC and $R_{a d j}^{2}$ values, but lowest RMSE, was considered to be an appropriate model for predicting stand volume.

\section{Results}

\subsection{MLR model}

MLR model showed that stand volume could be well predicted from stand age and basal area (Tab. 1). The model explained about $96 \%$ of the total variations in stand volume of Acacia mangium plantations. 
Table 1. Parameter estimates of the MLR and GWR models for predicting stand volume of Acacia mangium plantations

\begin{tabular}{c|c|ccc}
\hline Model & Statistics & \multicolumn{3}{|c}{ Model parameter } \\
& & Intercept $\left(\beta_{0}\right)$ & Age $\left(\beta_{1}\right)$ & Basal area $\left(\beta_{2}\right)$ \\
\hline MLR & Estimate & $-23.0447^{* *}$ & $3.3251^{* *}$ & $5.6403^{* *}$ \\
& Standard error (SE) & 1.003 & 0.145 & 0.094 \\
& $\beta_{i}-\mathrm{SE}$ & -24.048 & 3.180 & 5.547 \\
& $\beta_{i}+\mathrm{SE}$ & -22.042 & 3.470 & 5.734 \\
\hline GWR & Minimum & -41.030 & 1.419 & 3.975 \\
& $25 \%$ quartile & -24.630 & 2.841 & 5.339 \\
& Median & -22.340 & 3.165 & 5.640 \\
& $75 \%$ quartile & -19.060 & 3.480 & 6.060 \\
& Maximum & -14.230 & 6.177 & 6.901 \\
\hline
\end{tabular}

Note) ${ }^{* *}$ Significant at $p<0.001$

The regression coefficients for stand age and basal area were positive and significant $(p<0.001)$, meaning that stand volume increased at older stands and higher basal area. Obviously, MLR model only provided single coefficient for each independent variable, whereas variations in stand age and basal area were only measured by their standard errors. Compared to basal area, stand age had a higher standard error, meaning that it was more variable than basal area in their relationship to stand volume.

The predictive performance of MLR model seemed to be less accurate (Fig. 1a). The model underestimated stand volumes in the low range $(<$ $\left.12 \mathrm{~m}^{3} / \mathrm{ha}\right)$ and high range $\left(>60 \mathrm{~m}^{3} / \mathrm{ha}\right)$. There were also some obvious outliers in the middle range $\left(13-59 \mathrm{~m}^{3} / \mathrm{ha}\right)$, indicating overestimated stand volumes.

\subsection{GWR model}

Unlike MLR model, GWR model provided varying coefficients for each parameter (Tab. 1). Model intercepts varied from -41.03 to -14.23 , whereas local coefficients for stand age varied from 1.42 to 

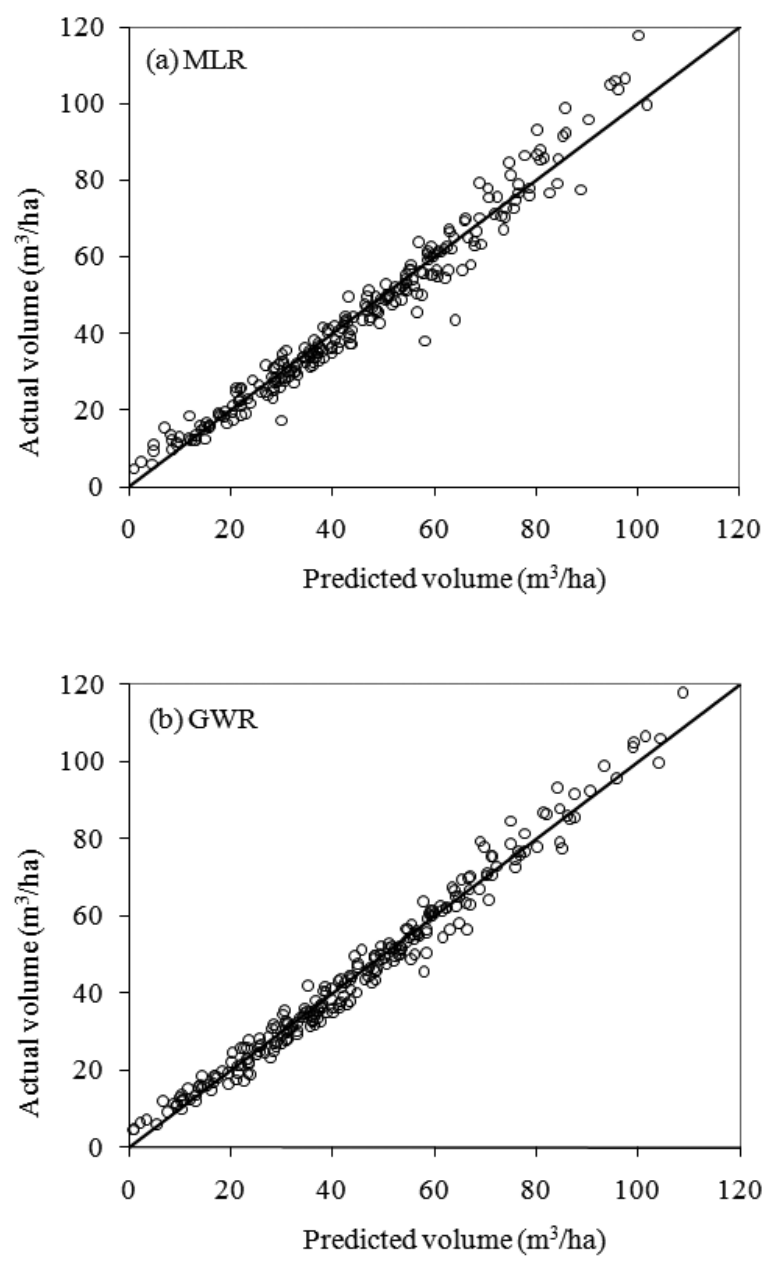

Figure 1. Scatter plots between predicted and actual stand volumes from (a) MLR and (b) GWR models

6.18, and those for basal area varied from 3.98 to 6.90 . The wider range of local coefficients for stand age indicated that local variations in stand age were greater than those in basal area. The local effects of 

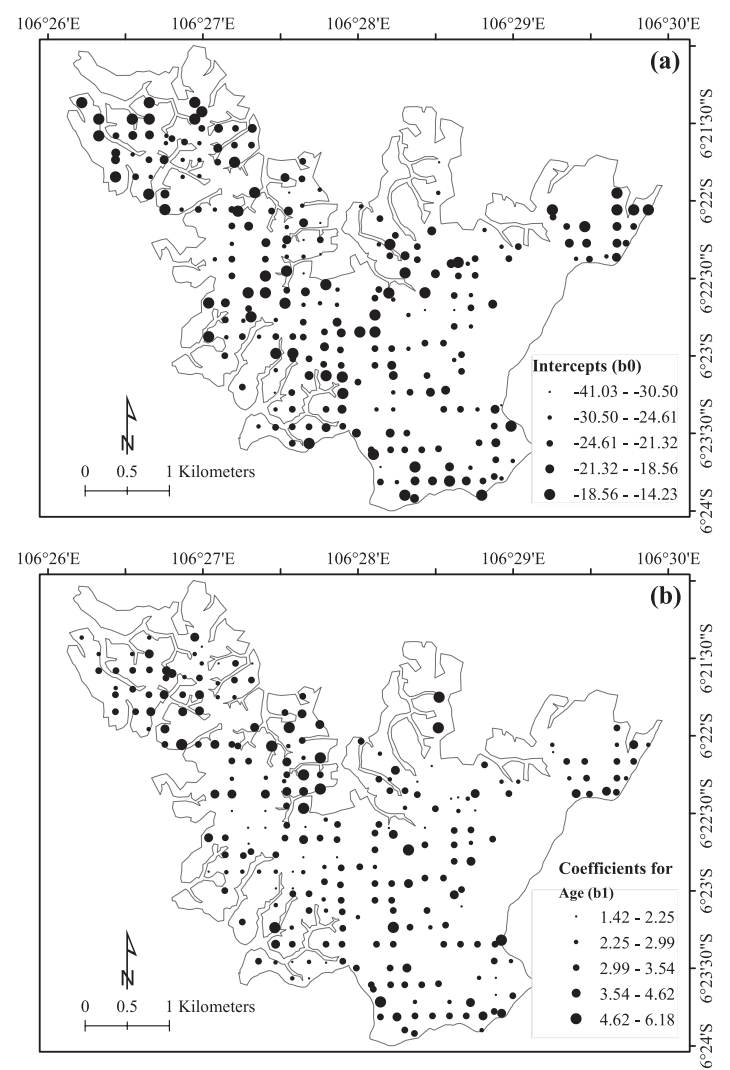

Figure 2. Spatial distribution of the local (a) intercepts, and (b) coefficients for stand age obtained from the GWR model

basal area to stand volume, however, were greater than those of stand age, because basal area had slightly higher local coefficients.

Spatial distribution of the model intercepts (Fig. 2a) showed that the effects of intercepts to stand volume estimates were different from one location to another. There was, indeed, non-stationary in the model intercepts because the inter-quartile range $(-24.630$ to -19.060$)$ of the GWR's intercepts was outside the range of $\beta \pm \mathrm{SE}(-24.048$ to -22.042$)$ 

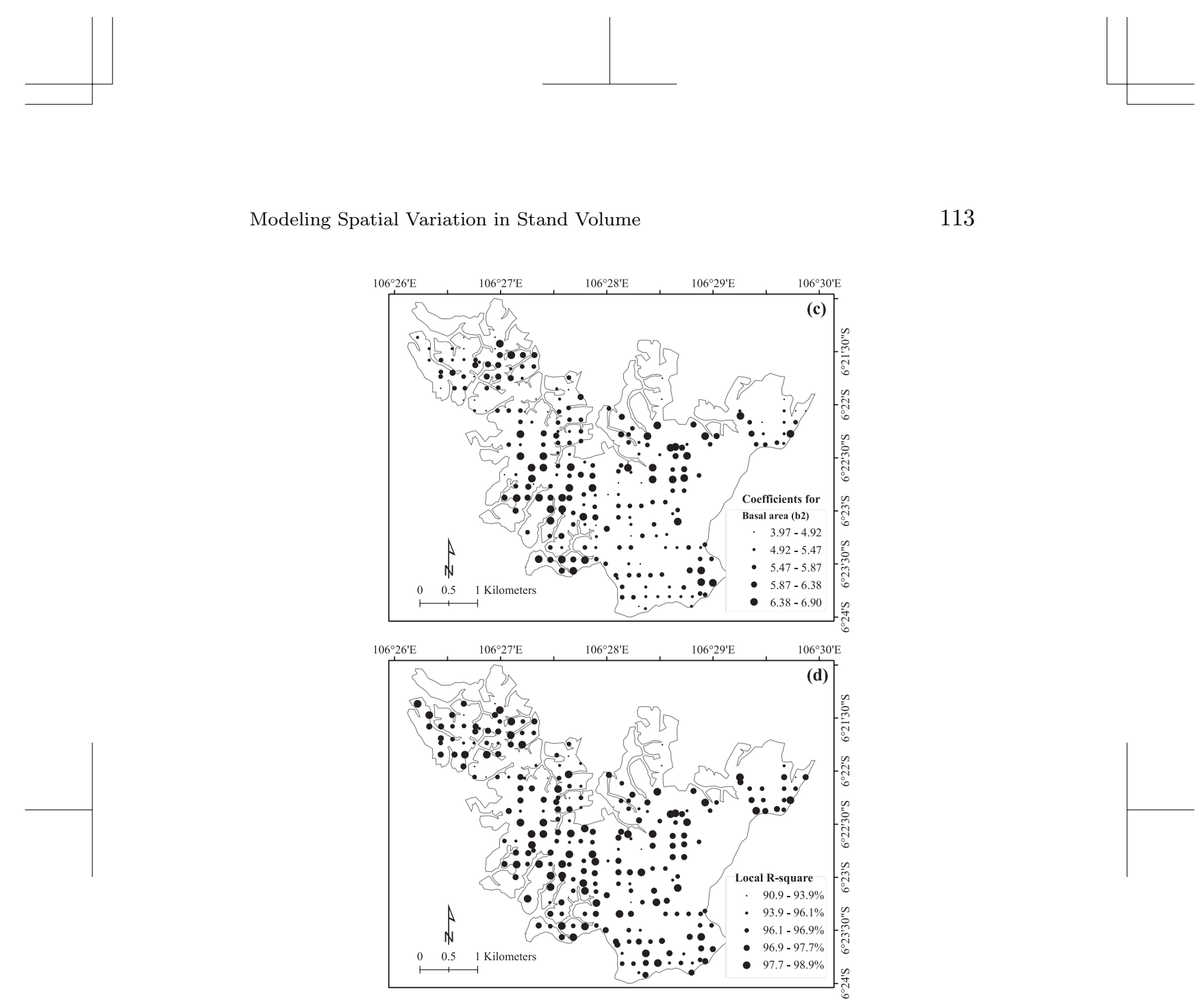

Figure 2. (cont.) Spatial distribution of the local (c) coefficients for basal area, and (d) adjusted coefficients of determination $\left(R_{a d j}^{2}\right)$ obtained from the GWR model

of the MLR's intercept.

Similar to the global model result, the local coefficients for stand age were also positive, meaning that local stand volumes tended to increase with increasing stand ages. GWR model, however, clearly showed that the effects of stand age to stand volume varied from one location to another (Fig. 2b), indicating that there was a non-stationary 
Table 2. Goodness-of-fit statistics of the MLR and GWR models

\begin{tabular}{c|ccc}
\hline Model & $R_{a d j}^{2}(\%)$ & RMSE & AIC \\
\hline MLR & 96.09 & 4.68 & 1468.35 \\
GWR & $90.89-98.87$ & 4.04 & 1442.24 \\
\hline
\end{tabular}

in stand age across the study area. The inter-quartile range of stand age (2.841 - 3.480), which was outside the range of $\beta \pm \mathrm{SE}(3.180-3.470)$ of MLR model, has also confirmed the presence of non-stationary in stand age (Tab. 1).

The local coefficients for basal area were also positive but slightly higher than those for stand age, meaning that local stand volumes increased at stands with higher basal areas. There were obvious clustered patterns in spatial distribution of the local coefficients of basal area (Fig. 2c). For instance, the lower parts of south-west areas had higher basal area effects than the lowest parts of north areas. The nonstationary of basal area was also indicated by the inter-quartile range $(5.339-6.060)$ of GWR model that was slightly beyond the range of $\beta \pm$ SE of MLR model (5.547 - 5.734, Tab. 1).

While the effects of local stand age and basal area could be expressed by their local coefficients, total variations in local stand volumes explained by these stand variables could be quantified by the local adjusted coefficients of determination $\left(R_{a d j}^{2}\right)$. The local $R_{a d j}^{2}$ values varied from $90.89 \%$ to $98.87 \%$ (Fig. 2d), showing that the majority (about $83 \%$ ) of sample plots were fitted by GWR with $R_{a d j}^{2}$ larger than that of MLR model $\left(R_{a d j}^{2}=96.09 \%\right)$. The spatial distribution of local $R_{a d j}^{2}$ values seemed to be similar with that of basal area (Fig. 2d, 2c), i.e., clustered spatial patterns, which indicated that the local variation of stand volume was more influenced by the local variation of basal area than stand age. 
Table 3. Coefficients of correlation

between local GWR coefficient estimates

\begin{tabular}{c|ccc}
\hline & Intercept $\left(\beta_{0}\right)$ & $\operatorname{Age}\left(\beta_{1}\right)$ & Basal area $\left(\beta_{2}\right)$ \\
\hline Intercept $\left(\beta_{0}\right)$ & 1.000 & -0.589 & -0.223 \\
$\operatorname{Age}\left(\beta_{1}\right)$ & & 1.000 & -0.647 \\
Basal area $\left(\beta_{2}\right)$ & & & 1.000 \\
\hline
\end{tabular}

Compared to MLR model, GWR model performed better in predicting local stand volume as indicated by their goodness-of-fit-statistics (Tab. 2). GWR model reduced AIC by $2 \%$ (about 26 scores), increased $R_{a d j}^{2}$ up to $3 \%$, and reduced RMSE by $14 \%$. The scatter plot between predicted and actual stand volumes (Fig. 1b) also showed that GWR model made remarkable improvements in the prediction of stand volume compared with that of MLR model (Fig. 1a). In addition, GWR model did not produce strong correlations between the local coefficient estimates (Tab. 3), indicating that multicollinearity among the local coefficients might not exist.

\section{Discussion}

The results showed that the effects of stand age and basal area were not constant over the study area, which resulted in the variability of stand volume of Acacia mangium plantations. This is reasonable because stand volume tends to vary from one location to another depending on their site productivities, which can be affected by natural and management factors (Skovsgaard and Vanclay, 2008). Although we lack of site index data to measure site productivity, the variations of stand volume in the lower, middle and higher ranges of Fig. 1 could indicate that site productivity varied over the study area. It was difficult to observe natural factors inherent to the plantation sites, but 
we recognized that thinning seems to be a possible management factor contributed to the variability of stand conditions. During the fieldwork, we observed that thinning varied considerably in their intensity and timing. Although the company has scheduled thinning periodically when stands reach 3,5 , and 7 years old, some stands at those ages were not thinned due to budget constraints. Such thinning practice would create variability in basal area and volume growths of the plantations, even within stands at a particular age. Vélez and Valle (2007) observed that frequent low thinning has caused the low growth of basal area and volume of Acacia mangium plantations in Colombia.

It is not surprising that MLR model produced less accurate predictions because this classical regression model does not take into account spatial variations in the stand variables. The MLR model only fitted a single function (Tab. 1) to all observations from various locations, hence its predictions might be close to the actual stand volumes at a certain location but it would be bias at other locations whose higher spatial variations in their basal area and stand age. Indeed, the model ignores a reality that stand volumes tend to vary according to local site conditions. It is reasonable if MLR model underestimated stand volume at the lower and higher ranges but it overestimated stand volume at the middle range (Fig. 1a), because this model does not consider the local spatial variations of stand variables. Similar result was also reported by Wang et al. (2005) who observed that MLR model underestimated net primary production (NPP) in the higher range but it overestimated NPP in the lower range.

On the other hand, GWR model indeed accounted for local spatial variations in the stand variables because it predicted stand volumes using appropriate local parameters derived from only several neighboring observations (instead of all observations as used in MLR model) within the bandwidth. A location dominated with smaller trees would have 
different model parameters to another location dominated with larger trees (Fig. 2), so that their predicted stand volumes would be different as well. Accordingly, local variations in site productivity of the plantations can be captured adaptively by GWR model, which resulted in more accurate predictions compared with those of MLR model. This result is consistent with previous studies (e.g., Zhang et al., 2004, Zhang and Shi, 2004, Wang et al., 2005, Kupfer and Farris, 2007, Kimsey et al., 2008), which proved that GWR model produced better prediction accuracy than classical regression techniques. In our study, about $83 \%$ of the local $R_{a d j}^{2}$ (Fig. 2d) was higher than the global $R_{a d j}^{2}(=0.961)$, indicating that GWR model produced a better explanatory ability with a greater accuracy (Fig. 1b) than MLR model. The model does not only account for the effects of stand age and basal area (as MLR model does), but it also integrates local spatial information that inherent to the stand variables (that cannot be captured by MLR model). These results are expected because forest managers will have more accurate stand volume estimates, hence uncertainty in estimating timber benefits could be reduced accordingly.

Despite the advantages, there are some possible shortcomings of GWR method. First, GWR (as also the case for other spatially-based methods) requires more data than MLR or other classical regression models. Unlike MLR, which is non spatially-based method, GWR also requires sample plots data with known geographical coordinates in order to predict local coefficients at a certain location based on neighboring observations. It should not be a serious problem, however, if the existing forest inventory provides extensive data in which the geographical coordinates of sample plots could be easily measured by using a GPS (Global Positioning System) device. Second, GWR could not directly produce predictions at un-sampled locations, unless the locations have known values of each independent variable (e.g., elevation, 
aspect, and normalized different vegetation index). It is therefore we could not able to produce surface map showing the spatial distribution of stand volumes over the study area, because there were no data for the stand age and basal area at un-sampled locations. When data for each independent variable are available at every location, such as those derived from a digital elevation model (DEM), it is possible to produce a map showing continuous predictions over space as demonstrated by Kupfer and Farris (2007) for predicting basal area as well as Kimsey et al. (2008) for predicting site index. When such data are unavailable, however, it is still possible to produce a surface map of a predicted variable by using geostatistics as demonstrated by Tiryana et al. (2009) for predicting carbon stocks in the study area. The last issue is that GWR may produce multicollinearity among local coefficients that can invalidate their interpretation (Wheeler and Tiefelsdorf, 2005). In our study, there were only moderate negative correlations between the local coefficient estimates (Tab. 3), so that the GWR results are still reliable. Nevertheless, as discussed by Wheeler and Tiefelsdorf (2005), GWR method would be more suitable for exploring spatial variations in stand attributes, but, it would be less appropriate for generating continuous spatial predictions.

\section{Conclusion}

This study showed that GWR model was able to reveal spatial variations in the relationship between stand volume, stand age, and basal area. The effects of stand age and basal area to stand volume varied considerably from one location to another, which might be caused by differences in thinning. Because the GWR model accounted for the local variations in the stand variables, it could produce better prediction accuracy than MLR model. It reduced AIC by $2 \%$, increased $R_{a d j}^{2}$ up to $3 \%$, and reduced RMSE by $14 \%$. The GWR models would there- 
fore be useful for exploring spatial variations in stand attributes, which could not be revealed by using ordinary regression models.

\section{Acknowledgement}

We gratefully acknowledge Perum Perhutani (especially Division of Forest Planning at Bogor) who permitted us to use the forest inventory data. We also thank Mr. Prianto (Bogor Agricultural University) and some staffs of Perum Perhutani at Tenjo forest district for their assistances during the field survey. Valuable comments and suggestions from a reviewer and editors have greatly improved the content of this manuscript.

\section{References}

Bivand, R. and Yu, D. (2009) spgwr: Geographically Weighted Regression, http://www.r-project.org (Accessed 5 February 2009).

Clutter, J. L., Fortson, J. C., Pienaar, L. V., Brister, G. H. and Bailey, R. L. (1988) Timber Management: A Quantitative Approach, John Wiley \& Sons, 333p.

Draper, N. R. and Smith, H. (1998) Applied Regression Analysis, John Wiley \& Sons, 706p.

Fang, J., Wang, G. G., Liu, G. and Xu, S. (1998) Forest biomass of China: an estimate based on the biomass-volume relationship, Ecol. Appl. 8: 1084-1091.

Fotheringham, A. S., Brunsdon, C. and Charlton, M. (2002) Geographically Weighted Regression: the Analysis of Spatially Varying Relationships, John Wiley \& Sons, 269p.

Husch, B., Beers, T. W. and Kershaw, J. A. (2003) Forest Mensuration, John Wiley \& Sons, 443p.

Kimsey, M. J., Moore, J. and McDaniel, P. (2008) A geographically weighted regression analysis of Douglas-fir site index in north central 
Idaho, Forest Sci. 54: 356-366.

Kupfer, J. A. and Farris, C. A. (2007) Incorporating spatial nonstationarity of regression coefficients into predictive vegetation models, Landsc. Ecol. 22: 837-852.

Miller, J., Franklin, J. and Aspinall, R. (2007) Incorporating spatial dependence in predictive vegetation models, Ecol. Model. 202: 225242.

Perum Perhutani (2006) The Yield Regulation Plan for Acacia mangium Plantations for the Period of 2006-2010, Perum Perhutani Unit III (in Bahasa Indonesia).

R Development Core Team (2009) R: A Language and Environment for Statistical Computing, http://www.R-project.org (Accessed 5 February 2009).

Skovsgaard, J. P. and Vanclay, J. K. (2008) Forest site productivity: a review of the evolution of dendrometric concepts for even-aged stands, Forestry 81: 13-31.

Tiryana, T., Tatsuhara, S. and Shiraishi, N. (2009) Applicability of kriging to predict spatial distribution of carbon stocks of Acacia mangium plantations, J. Forest Plann. 14: 17-26.

Vélez, D. A. T. and Valle, J. I. D. (2007) Growth and yield modelling of Acacia mangium in Colombia, New Forests 34: 293-305.

Wang, Q., Ni, J. and Tenhunen, J. (2005) Application of a geographically-weighted regression analysis to estimate net primary production of Chinese forest ecosystems, Global Ecol. Biogeogr. 14: 379-393.

Wheeler, D. and Tiefelsdorf, M. (2005) Multicollinearity and correlation among local regression coefficients in geographically weighted regression, J. Geograph. Syst. 7: 161-187.

Zhang, L., Bi, H., Cheng, P. and Davis, C. J. (2004) Modeling spatial variation in tree diameter-height relationships, Forest Ecol. Manag. 
189: 317-329.

Zhang, L. J. and Shi, H. J. (2004) Local modeling of tree growth by geographically weighted regression, Forest Sci. 50: 225-244.

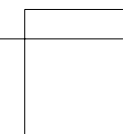




\section{地理的加重回帰を用いた Acacia mangium 人 工林林分材積の空間的な変動のモデル化}

タタン·ティリアーナ・龍原 哲・白石 則彦

要約:

林分材積は重回帰 (MLR) モデルや他の通常の回帰モデルを用いることに よって, 他の林分変数から推定することができる. しかし, MLR では対象 地全体を対象としたパラメータしか推定できないため, 林分変数の空間的変 動を示すことができない. 本研究では, 地理的加重回帰 (GWR) を用いて, Acacia mangium 人工林における林分材積と, 樹齢, 胸高断面積との関係 の空間的変動を調べるとともに, GWR モデルが MLR モデルより予測精 度が良いかどうかを調べた. 人工林内に設置された 247 個の区画から林分 データと地理座標を得た．林分材積を樹齢と胸高断面積に関連させる線形モ デルを定式化し，MLR と GWR を用いてデータを解析した. パラメータ の推定值と適合度検定統計量によって GWR モデルと MLR モデルを比較 した. その結果, GWR モデルは林分材積と樹齢, 胸高断面積との関係の空 間的変動を示すことができるだけでなく, MLR モデルより予測精度が良い ことが示された. GWR モデルは MLR モデルと比較し, AIC を $2 \%$ 減少 させ, $R_{a d j}^{2}$ を $3 \%$ まで増加させ, RMSE を $14 \%$ 減少させた. したがって, GWR モデルは, 普通の回帰モデルによって示すことができない林分属性の 空間的変動をモデル化する上で有用であるといえる.

キーワード： 林分材積, 空間変動, 地理的加重回帰地理的加重回帰 (GWR) 